\title{
STUDENTS' LEARNING AUTONOMY: A SYSTEMATIC LITERATURE REVIEW
}

\author{
Rui Pedro Lopes ${ }^{1}$, Cristina Mesquita², Lourival Aparecido de Góis ${ }^{3}$, Guataçara \\ dos Santos Junior ${ }^{3}$ \\ ${ }^{1}$ Research Center in Digitalization and Intelligent Robotics, Instituto Politécnico de Bragança \\ (PORTUGAL) \\ ${ }^{2}$ Research Center in Basic Education, Instituto Politécnico de Bragança (PORTUGAL) \\ ${ }^{3}$ Universidade Tecnológica Federal do Paraná (BRAZIL)
}

\begin{abstract}
Higher education finds a set of challenges covering several areas and sectors, resulting from the increasing number of students, their academic and cultural diversity, the demands of the labor market, among others. This massification of training, coupled with budgetary and infrastructural constraints, the uncertainty in the renewal of teaching and non-teaching staff within the requirements to maintain quality and high levels of success, requires creative pedagogical methodologies, especially in the first year, where students face the highest dropout and unsuccess ratio. In this context, Higher Education Institutions encourages teachers to reflect on these issues, providing pedagogical training opportunities and encouragement to implement alternative pedagogical practices, in order to diversify the methodologies so that they can be better adapted to different students' profile.

However, there is still no concern to help the student to organize their autonomous study time. Students have considerable difficulties organizing their personal study time. The fragmentation of the schedule, the distribution of theoretical classes, articulation with the practical learning experiences and the lack of planning of the non-classroom time aggravate the difficulties in time organization. A good organization and planning are fundamental for fostering students' persistence, motivation and, consequently, provide the possibility for higher success ratios.

This study seeks to survey the challenges faced by students and teachers in organizing autonomous study time. Based on a systematic literature review, the definition of concepts, impact of time organization in the students' success, and the institutional concern with the autonomous learning time (non-presential hours) are researched. It is observed that the difficulty is considerable, although few initiatives are taken to help the students to achieve better organization and a better autonomous learning process.
\end{abstract}

Keywords: autonomous learning; higher education; systematic literature review.

\section{INTRODUCTION}

The Bologna Process reveals itself to the signatory countries as an opportunity for the renewal of Higher Education. The central issue is expressed in "quality assurance" in higher education, with profound implications for the organization of degrees, curricula, methodologies, organizational structure of institutions and, above all, teaching-learning approaches.

At first, the Bologna Process was manly a policy, administrative measure that had its greatest expression in the change of curricula, hours and organization, but with few organizational and pedagogical reflexes. There is, however, awareness that the Bologna Process "has brought with it unprecedented reform across the European continent in terms of the huge efforts undertaken to make higher education programmes more transparent and comparable and to make higher education students and staff more mobile across the European Higher Education Area (EHEA)" [1].

However, the philosophy behind this project of transformation of higher education has involved a reflection on the ECTS (European Credit Transfer System), the qualification and training of teachers, the governance, organization and equipping of institutions, access, success and school outcomes, the educational environment of the involvement of HEls with the community, educational innovation, performance standards, teaching-learning methodologies, student assessment and strengthening social trust in higher education. The adoption of ECTS, which leads to the international mobility of students, has been redefining the mutually recognized assessment and quality assurance schemes and the Supplement to the Diploma. 
The ECTS system is focused on the student and is based on the time and effort that he expends in the accomplishment of the set of tasks inherent to his full learning, defining also a direct link between ECTS and the number of classroom hours with the teacher. It assumes that the full-time workload over an academic year corresponds to 60 credits. The workhours include: theoretical classes, practical classes, theoretical-practical classes, individual and group research times, report writing, presentation of classes / themes, which calls for a very intense and deep articulation between the teachers of each course and between these and their students (with support of web platforms or other technological resources).

The workload required for a student to achieve the objectives of a particular Course Unit is thus dependent on each student's work skills, the level (introductory or advanced) of the objectives and contents assigned to each Unit and the teaching-learning methods. The process puts great emphasis on the student, encouraging higher education institutions (HEls) and academic staff to place students at the centre of their thinking and to help them manage their expectations and be able to consciously and constructively design their learning paths throughout their higher education experience [1].

In this framework, the student's autonomous work assumes a fundamental value in learning. It is important that they know and recognize what is being studied and the objectives to be achieved, that they know how to define work tasks and priorities, to know how to use and to enjoy the numerous information resources, to study, to write summaries and to prepare reading sheets and reports be persistent to take the work to the end.

According to Azevedo [2], working with autonomy also implies a lot from the educational institution and the teachers. Stimulate the autonomous study of the students implies the availability of resources and good sources of information, availableness in weekly schedules to support the development of tutorial work, continuous, quality and ready feedback, require effort and support for their persistence in work, and find strategies to support differently the different rhythms.

Thus, it is understandable that work with autonomy involves the HEI a great organizational and educational efforts around the objectives and teaching practices. Action-training projects that involve teams of teachers become relevant, and it is necessary to review and redefine spaces for tutoring and group work, which are much more frequent, qualify the educational space, create an environment of opportunity, stimulating and challenging learning.

These efforts have been carried out by several HEls, and there are already in the scientific literature a considerable number of pieces of research that highlight the importance and constraints of students' autonomous work and the teaching practices that stimulate them. This work intends to know these trends that have been assumed by the institutions and teachers of the HEI for the development of the autonomous work of the students.

This paper explores, through a systematic literature review, the impact of the self-study in higher education and its relationship with the development of autonomy in students.

\section{METHODOLOGY}

The main objective of this literature review is to try to understand what the role of self-study in higher education is, in respect to students' autonomy development. Additionally, it is also important to understand how it is defined and how it is implemented. This literature review follows the approach suggested by Materla, Cudney and Antony [3] and by Subhash and Cudney [4], including three phases: planning, operation and dissemination (Figure 1). 

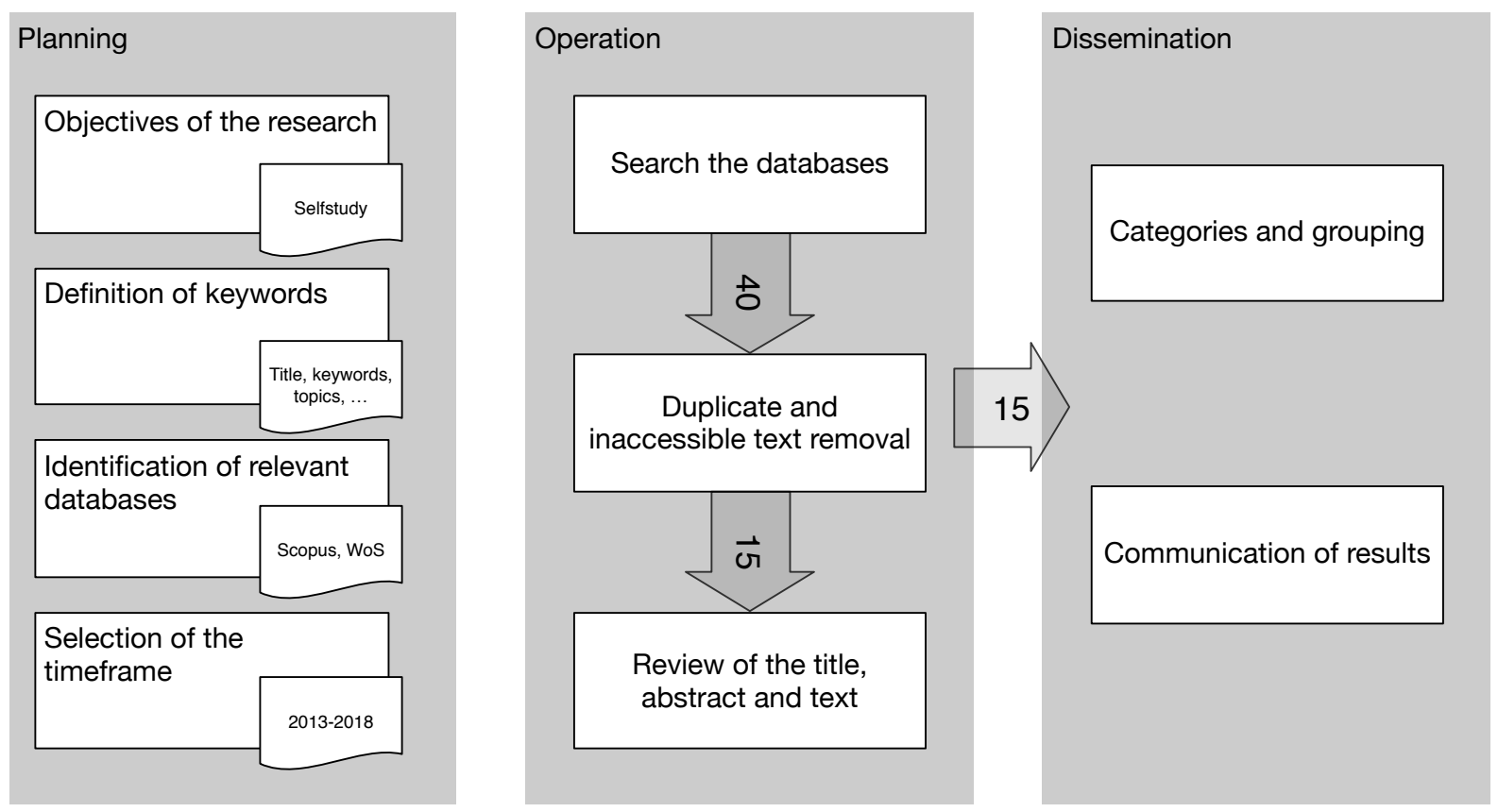

Figure 1. Phases and results of each step.

The papers were searched in Scopus and Web of Science. The key terms used consisted as the search term "Autonomy AND Self-study", used both in title and topic.

These databases were selected because they provide a wide set of areas and the key terms provide an initial focus on the main objective of this work. A total of 40 papers were identified in the first run (Table 1).

Table 1. Search terms and the number of papers retrieved.

\begin{tabular}{l|l|c}
\hline \multicolumn{1}{c|}{ Database } & \multicolumn{1}{|c}{ Search term } & Results \\
\hline Scopus & TITLE-ABS-KEY ( autonomy AND self-study ) & 16 \\
\hline Web of Science & TOPIC:(autonomy and self-study) & 24 \\
\hline & Total & 40 \\
\hline
\end{tabular}

Only the papers retrieved from Scopus and Web of Science published between January $1^{\text {st }}, 2013$ and December $31^{\text {st }}, 2018$, whose text were available in the institutional repositories were considered. Moreover, papers without a peer review process and written in a different language than English were also excluded. After removing the duplicate entries, the total number of papers were 30 . Of these, only 15 had the text available in PDF. After an analysis of the title, abstract and text, 2 more papers were excluded for being out of the scope of this work. A total of 15 papers remained for the analysis.

Some guidelines were defined for the text analysis, with the purpose of identifying the concept of selfstudy and how this could be used by the authors and its relationship with the development of student autonomy. Finally, the identification of difficulties and success factors.

\section{ANALYSIS AND DISCUSSION}

The analysis process started with the characterization of the selected references. A content analysis followed, to assess the context and definition of self-study and the purpose of the work described in the paper.

\subsection{Characterization}

In total, papers from 13 countries were found (Figure 2). China and USA have two papers each and the remaining countries a single paper was found. 


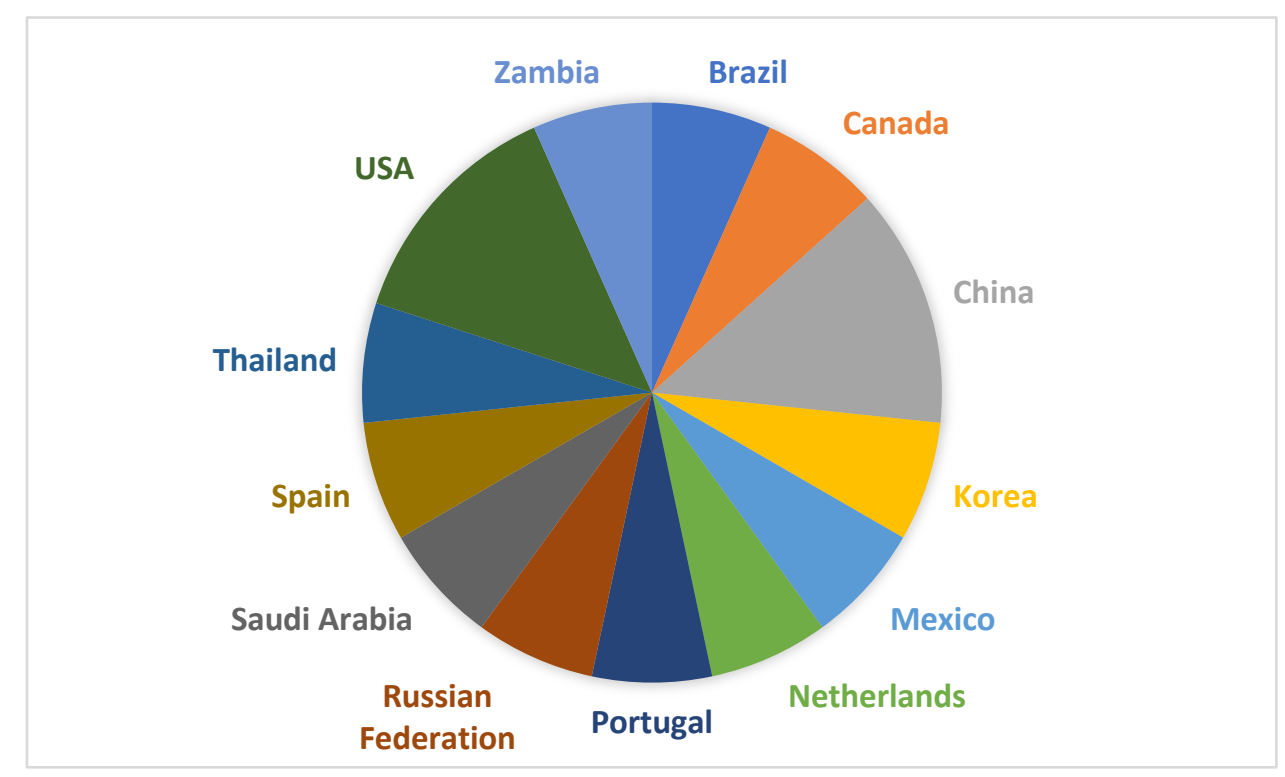

Figure 2. Paper distribution by country.

The distribution by year reveal a peak number of papers around 2016-2017, followed by a year without a single one (Figure 3).

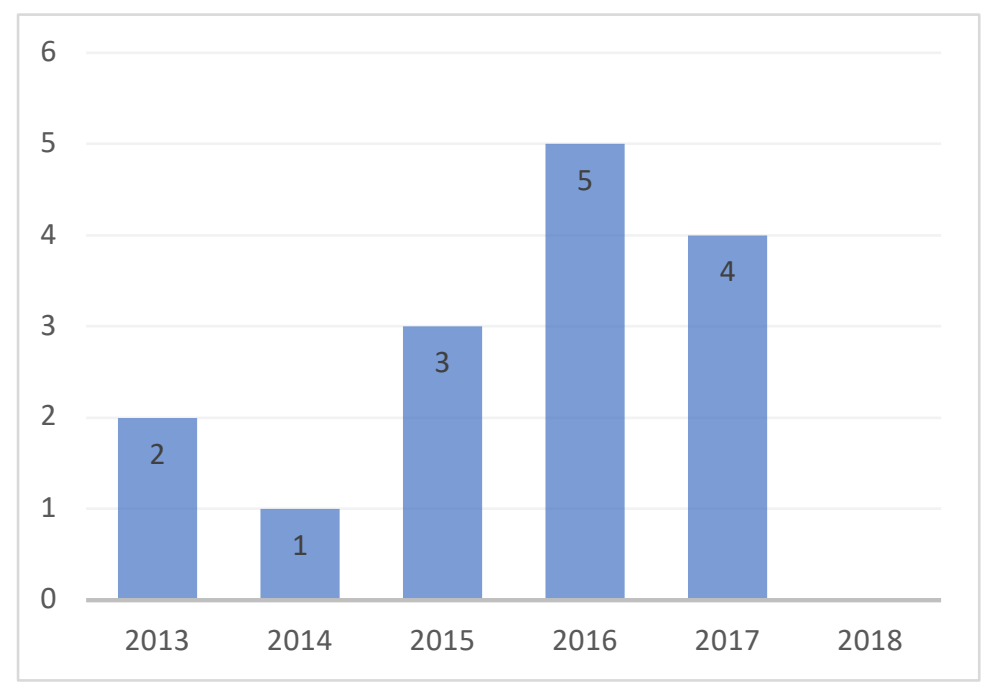

Figure 3. Paper distribution by year.

In relation to the concept of self-study, according to the papers, three interpretations can be found. One, which we designate self-regulated study, assumes the student as the responsible for his own time and effort, towards working with the purpose of developing knowledge related to a subject or area. Kusurkar, Croiset, Galindo-Garre and Ten Cate "found that intrinsic motivation was significantly positively correlated with deep strategy towards study [...], self-study hours, and significantly negatively correlated with surface strategy towards study [...] and exhaustion from study", meaning a direct influence between academic success and self-study [5]. In other words, the authors cross medical students' motivation levels with the amount of good study time, resilience to exhaustion and good academic performance.

Another interpretation considers self-study as a guided process of study, with the support of online tools or assignments. Although the student is working alone, the learning experiences are prepared for him to complete a specific task or study a specific content. Yin and Wang, for example, mention that "university teaching should change from the dependence on teachers' lecture to students' self-study, student-centred approaches, such as hands-on activities and problem-based learning" [6]. Zeng considers that "autonomous learning is achieved on certain conditions: motivation, attitudes, learning 
strategies, cognitive styles and evaluation, etc. Therefore, it is very necessary for teachers to pay much attention to these factors for the aim of developing students' autonomy in English learning" [7].

The last interpretation considers self-study as the process of understanding the subject's own action, through some research material or instruments. These typically include field notes, reflection reports or others. For example, "the self-study presented in this article examines my experiences in teaching and mentoring student teachers through collaborative reflections applying reflective questions strategy during residential teaching practice" [8].

In relation to the context of the self-study, it is possible to identify five main areas (Figure 4). All the areas have three papers, except foreign language learning that includes only two. These support selfstudy (or self-regulated study, although the authors do not use this terminology), to support foreign language learning outside class hours. Students are stimulated to use online tools, autonomously, to perform assignments and practice foreign language skills. According to Kim, "learners can improve their oral proficiency through independent study by using online self-study resources, online recording program and speech-text-program (STP), and feedback in an autonomous learning environment" [9].

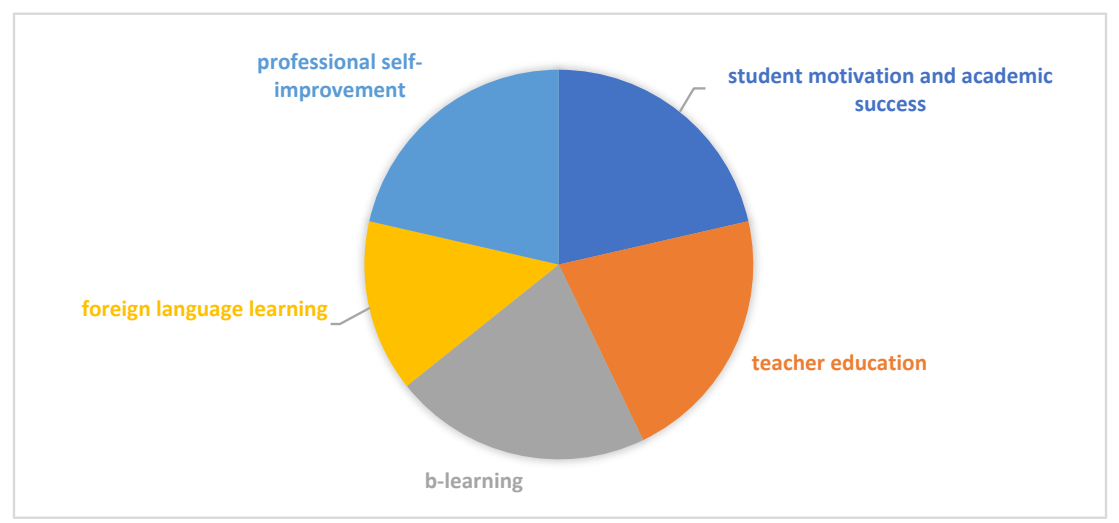

Figure 4. Context of the self-study mentioned in the papers.

Following the chart clockwise, professional self-improvement describes self-regulated study as a mean to improve the professional activity. In this situation, professionals reflect and study on their activity so that they can improve their productivity or professional development. Self-study "as a research framework has a few features that distinguish it from other forms of teacher research: focus on the role of the self as creator and investigator in the teaching environment, the role of critical friends, and the careful documentation followed by reflection about teaching practice" [10]. In addition, in the medical area, "most physicians believed the CPG is a good starting point for their self-study and would like to know more about it before they decide to implement it" [11]. Keck refers that "selfunderstanding through self-study is ongoing, complex and demanding work. Uncovering deeply held assumptions about practice is a challenging task because an individual's patterns of behaviour, particularly those long-held and deeply engrained behaviours, can be hard to uncover and resistant to examination" [12].

Student motivation and academic success describes the situations that students are stimulated to increment their self-regulated study to foster their academic success. The use of specific tools or learning experiences can contribute to increase the motivation of students and, thus, stimulate the autonomy and self-study. For example, Morais, Hirano, Araujo and Nery [13] describe that using "concept maps in teaching Geography brings up the idea of the development and the exercise of students' autonomy, since self-learning is one of the essential factors to make meaningful learning of spatial content classroom occur".

Teacher education describes the reflective activities used by future teachers to improve their professional competences in context. It is usually associated to the practicum in the teacher education programmes curriculum. The adoption of self-study methodology, "major results is that the motivational climate [...] was improved across the duration of the study" [14]. Barbosa and Vieira also consider that "self-study inquiry into the pedagogy of teacher education [...] shows that teacher educators can challenge the status quo by developing a scholarship of teacher education" [15]. Moreover, "self-study focuses on the ways in which my deeper understanding of the relationships teacher candidates develop with their cooperating teachers during practicum experiences has reframed my approach to teaching curriculum methods courses" [16]. 
Finally, $b$-learning describes the online tools that support self-regulated study and that are later complemented with presential, in class, activities and learning experiences. Banditvilai also adds that it "combines self-study with valuable face-to-face interaction with a teacher. This study puts the spotlight on learning outcomes in an English for Specific Purposes" [17]. This is further complemented with "learner- and activity-centred approach in our study has the task of finding ways to optimize and improve the performance of students' independent work of non-language specialties through a foreign language" [18].

They seem to agree that self-study is both an expression of motivation and a fundamental tool to foster deep degree of learning and high potential for academic success. There is still some work to do in relation to the development of autonomy and student workload management.

\section{CONCLUSIONS}

Universities are required to provide adequate learning environment to students, to maximize their possibilities for learning and academic development. The Bologna process defined the European Higher Education Area, that contributes to wide recognition of training and learning experiences across several signatory countries. Strong academic results are tied to high motivation levels that, in turn, are associated with intense and autonomous self-study methods. The self-study term is used, in the literature, with three different contexts, namely, the independent study time that students perform, the study of the self-actions towards self-improvement and professional development and the reflection on the learning process, usually associated to the in-context training in teacher education.

The work presented in this paper performed a systematic review of the literature with the objective to assess the definition of self-study and the impact on students' autonomy in higher education. The main databases were searched, and 14 papers were retrieved, focusing these three contexts. All of the authors are of the opinion that, in each context, self-study is an important tool to foster academic success, help in the professional development and better learn and be prepared for the profession.

Based on the short number of results, there is still a lot of work to do in relation to the development of student autonomy and the motivation toward self-study. Universities should reflect on this issue and test and consider approaches that can lead students to higher degree of autonomy and success.

\section{REFERENCES}

[1] A. Attard, E. Di loio, K. Geven, and R. Santa, "Student centered learning: an insight into theory and practice," European Student Union, Bucharest, Romania, 2010.

[2] J. Azevedo, "Secundário-Superior: o trabalho autónomo dos alunos," Lisboa, 2010.

[3] T. Materla, E. A. Cudney, and J. Antony, "The application of Kano model in the healthcare industry: a systematic literature review," Total Qual. Manag. Bus. Excell., vol. 0, no. 0, pp. 1-22, May 2017.

[4] S. Subhash and E. A. Cudney, "Gamified learning in higher education: A systematic review of the literature," Comput. Hum. Behav., vol. 87, pp. 192-206, Oct. 2018.

[5] R. A. Kusurkar, G. Croiset, F. Galindo-Garre, and O. Ten Cate, "Motivational profiles of medical students: Association with study effort, academic performance and exhaustion," Bmc Med. Educ., vol. 13, Jun. 2013.

[6] H. Yin and W. Wang, "Assessing and improving the quality of undergraduate teaching in China: the Course Experience Questionnaire," Assess. Eval. High. Educ., vol. 40, no. 8, pp. 1032-1049, 2015.

[7] X. Zeng, "Research on Autonomous Learning in English in Higher Education," in Proceedings of the 6th International Conference on Mechatronics, Computer and Education Informationization (MCEI 2016), 29 AVENUE LAVMIERE, PARIS, 75019, FRANCE, 2016, vol. 130, pp. 924-927.

[8] T. G. Mukeredzi, "Creating space for pre-service teacher professional development during practicum: A teacher educator's self-study," Aust. J. Teach. Educ., vol. 40, no. 2, pp. 126-145, 2015.

[9] S. Kim, "Developing autonomous learning for oral proficiency using digital storytelling," Lang. Learn. Technol., vol. 18, no. 2, pp. 20-35, 2014. 
[10] M. A. Hjalmarson, "Learning to teach mathematics specialists in a synchronous online course: a self-study," J. Math. Teach. Educ., vol. 20, no. 3, pp. 281-301, 2017.

[11] L. Alnaim and S. Almaz, "A study of barriers and facilitators of clinical practice guidelines implementation among physicians," Indian J. Pharm. Sci., vol. 79, no. 6, pp. 923-929, 2017.

[12] C. Stephen Keck, "Getting to the heart of teacher experience: The journeying of reflexivity, selfstudy and conscious attention," INNOVACION Educ.-Mex., vol. 15, no. 67, pp. 21-47, Apr. 2015.

[13] M. A. Morais, F. W. Hirano, T. Araujo, and G. Nery, "Use of concept maps as a strategy for teaching-learning and assessment tool in geography lessons," in CEUR Workshop Proceedings, 2016, vol. 1667, pp. 139-146.

[14] J. L. Langdon, R. Schlote, B. Melton, and D. Tessier, "Effectiveness of a need supportive teaching training program on the developmental change process of graduate teaching assistants' created motivational climate," Psychol. Sport Exerc., vol. 28, pp. 11-23, 2017.

[15] I. Barbosa and F. Vieira, "Making a difference in teacher education? A case study," Int. J. Learn. High. Educ., vol. 20, no. 1, pp. 31-43, 2013.

[16] S. M. Bullock, "Understanding Candidates' Learning Relationships with their Cooperating Teachers: A call to Reframe my Pedagogy," Stud. Teach. Educ., vol. 13, no. 2, pp. 179-192, 2017.

[17] C. Banditvilai, "Enhancing students' language skills through blended learning," Electron. J. ELearn., vol. 14, no. 3, pp. 220-229, 2016.

[18] U. S. Borisova and G. M. Parnikova, "Methodological approaches and pedagogical conditions of the educational autonomy formation in students - Natives of Yakutia," Math. Educ., vol. 11, no. 10, pp. 3397-3403, 2016. 